\title{
UPAYA MENCIPTAKAN LINGKUNGAN YANG SEHAT MELALUI PEMBUATAN MCK BAGI WARGA KAMP PENGUNGSI TIMOR BARAT
}

\author{
Kristomus Boimau'), Rima N. Selan ${ }^{1}$, Adi Y. Tobe ${ }^{1)}$, Jack C. Pah ${ }^{1)}$ \\ 1)Jurusan Teknik Mesin, Fakultas Sains dan Teknik, Universitas Nusa Cendana, Kupang, NTT, Indonesia \\ Corresponding author:Kristomus Boimau \\ E-mail: kristomus.boimau@staf.undana.ac.id
}

\section{Diterima 12 November 2020, Direvisi 16 November 2020, Disetujui 17 November 2020}

\begin{abstract}
ABSTRAK
Kamp pengungsi Dilor Tuapukan adalah salah satu contoh kamp pengungsi di Timor Barat yang masih dihuni oleh pengungsi sejak tahun 1999. Kamp pengungsi seluas $\pm 2,25$ ha (150 m x $150 \mathrm{~m}$ ) ini dihuni oleh $111 \mathrm{KK}$ dengan jumlah jiwa sebanyak 275 orang. Seluruh KK tinggal di rumah darurat yang tidak layak huni sesuai standar rumah sehat dengan kondisi ALADIN (atap, lantai, dinding) seadanya yakni atap dari daun gewang, dinding dari bebak/pelepah dan lantai tanah. Selain itu, ketersediaan MCK pun sangat kurang, bahkan mayoritas KK ( $\pm 85 \%)$ di kamp ini tidak memilik MCK sendiri, sehingga mereka memanfaatkan kebun di sekitar kamp untuk buang air besar (BAB). Dari hasil pantauan di wilayah kamp pengungsi Dilor terlihat ada sebuah MCK permanen, 12 MCK darurat berdinding daun gewang tanpa closet. Saluran pembuangan air dari MCK pun macet sehingga air tergenang disepanjang saluran. Hal ini tentu menciptakan lingkungan yang tidak sehat. Tidak tersedianya MCK yang layak sesuai standar kesehatan disebabkan karena keterbatasan dana untuk membangun MCK serta ketidakpahaman warga akan pentingnya kesehatan lingkungan. Tujuan dari kegiatan ini adalah untuk mengatasi ketidaktersediaan MCK dengan membuatkan MCK umum bagi warga. Kegiatan ini dilaksanakan selama 2 bulan dan menghasilkan 2 unit MCK permanen dengan masing-masing MCK memiliki 3 kamar. Setelah MCK selesai dibuat dan digunakan, selanjutnya tim pelaksana melakukan monitoring ke lokasi setiap 2 minggu sekali untuk memantau aktifitas warga dalam menggunakan MCK. Hasilnya menunjukkan bahwa warga tidak buang air besar (BAB) sembarangan.
\end{abstract}

Kata kunci: kamp pengungsi; lingkungan; MCK.

\begin{abstract}
The DilorTuapukan refugee camp, is one of the refugee camps in West Timor that has been inhabited by refugees since 1999. The area of this camp is approximately 2.25 hectares $(150 \mathrm{~m} \times 150 \mathrm{~m})$. This refugee camp is inhabited by 111 families with a total of 275 people. The whole family lives at emergency houses. The houses are not suitable for habitation (viewed from the Healthy Home Standard). The condition of the houses that they live in, especially in terms of ALADIN (roof, floor, walls) conditions is very unhealthy and very simple. The roof of the houses are made of Gewang Leaves, the walls are made of Bebak / Midrib and the floor are made of land only. In addition, the availability of facilities for bathing, washing clothes, and defecating (MCK) are very lacking. The majority of families ( $\pm 85 \%)$ in this camp do not have their own toilet. To carry out the MCK activities, they used the garden around the camp. For example, to defecate (BAB) is stiffened in the garden area. From the results of monitoring in the area of the Dilor refugee camp, it can be seen that there is a permanent toilet only, 12 emergency toilets with Gewang leaf walls without watercloset. The drainage channel from the toilets was jammed, so that the water was stagnant along the channel. This certainly creates an unhealthy environment. The unavailability of proper toilets according to health standards, are due to limited funds to build toilets, and residents' lack of understanding of the importance of environmental health. Therefore, to overcome the unavailability of toilets, the implementation team will make public toilets for residents. This activity was carried out for 2 months, and has succeeded build 2 permanent MCK units with each MCK having 3 rooms.
\end{abstract}

Keywords: refugee camp; environment; MCK.

\section{PENDAHULUAN}

Referendum atau Jajak Pendapat bagi rakyat Timor-Timur yang disponsori oleh Perserikatan Bangsa-Bangsa PBB pada tahun 1999 hingga kini masih menyisakan banyak masalah bagi mereka yang masih bertahan di kamp pengungsi di wilayah Timor Barat (Pulau Timor - NTT). Gejolak Politik di Timor Timur pasca 
jajak pendapat tanggal 30Agustus 1999 yang mengakibatkan lepasnya Provinsi Timor-Timur dari Indonesia, telah menyebabkan eksodus atau pengungsian wargaTimor Timur dalam jumlah besar dari wilayah Timor-Timur ke beberapapropinsi di Indonesia(Moh Soehadha, 2019).

Akibat Jajak Pendapat atau Referendum yang dimenangkan oleh kelompok Pro-kemerdekaan, menyebabkan laju para pengungsi ke berbagai wilayah Timor BaratIndonesia meningkat drastis bahkan menjadi puncak dalam sejarah pelarian orang-orang Timor-Timur akibat berbagai konflik dan perang saudara di kampung halamannya. Pengungsi yang bermukim di Timor Barat telah menimbulkan berbagai dampak bagi kehidupan sosial, ekonomi, dan keamanan masyarakat Nusa Tenggara Timur,khususnya yang berada pada pusat-pusat pengungsian. Gangguan ketertiban dan keamanan yangdilakukan oleh pengungsi terhadap penduduk asli, seperti pembakaran rumah - rumah penduduk,sekolah-sekolah dan aset-aset masyarakat lainnya(Mulia, 2014).

Sebagian kecil pengungsi telah memiliki pekerjaan tetap di Indonesia khususnya di Timor Barat (NTT). Ada yang bekerja sebagai PNS, guru, polisi, tentara, pedagang, sopir, dan ojek. Namun sebagian besar berprofesi sebagai buruh kasar (bangunan) dan buruh tani dengan cara mengerjakan lahan sawah/kebun milik warga asli kemudian hasilnya dibagi dengan pemilik lahan.

Perilaku masyarakat merupakansemua hal yang dilakukan masyakat dalam bentuk tindakan nyata dalam merespons rangsangan yang ada.Teori tindakan tersebut, terkandungkonsep bahwa dalam hal menganalisa suatu kebudayaan dalam keseluruhan perlu dibedakan secara tajam antara adanya empat komponen, yaitu; (1) sistem budaya, (2) sistem sosial, (3) sistem kepribadian, dan (4) sistem organisme. Keempat komponen itu, walaupun erat berkaitan satu dengan yang lain, masih merupakan entitas yang khusus, masingmasing dengan sifat-sifatnya sendiri (Sutoyo et al., 2019).

Kamp pengungsi Dilor Tuapukan adalah salah satu contoh kamp pengungsi di Timor Barat yang masih dihuni oleh pengungsi sejak tahun 1999. Kamp pengungsi seluas \pm 2,25 ha $(150 \mathrm{~m} \times 150 \mathrm{~m})$ ini dihuni oleh $111 \mathrm{KK}$ dengan jumlah jiwa sebanyak 275 orang. Seluruh KK tinggal di rumah darurat yang tidak layak huni sesuai standar rumah sehat dengan kondisi ALADIN (atap, lantai, dinding) seadanya yakni atap dari daun gewang, dinding dari bebak/pelepah gewang serta berlantai tanah. Selain itu, sebagian besar rumah tangga yakni 95 KK tidak memiliki MCK sesuai standar, sehingga mereka memanfaatkan kebun di sekitar kamp untuk buang air besar (BAB). Hal ini tentu berdampak pada sanitasi yang buruk. Dari hasil pantauan di wilayah kamp pengungsi Dilor terlihat ada sebuah MCK permanen, 12 MCK darurat berdinding daun gewang tanpa closet (gambar 1). Saluran pembuangan air dari MCK pun macet sehingga air tergenang disepanjang saluran. Hal ini tentu menciptakan lingkungan yang tidak sehat, bahkan saat musim hujan, seluruh wilayah kamp becek dan berlumpur.

Tidak tersedianya MCK yang layak sesuai standar kesehatan dan SNI (Nasional, 2002). Hal ini disebabkan karena keterbatasan dana untuk membangun MCK serta ketidakpahaman warga akan pentingnya kesehatan lingkungan. Sedangkan kebutuhan air bersih cukup terpenuhi 3 buah sumur gali dengan kedalaman 10 meter yang airnya tersedia sepanjang tahun.

Tata cara perencanaan MCK sebenarnya sudah distandarisasi dan terdapat tigasarana yang penting sarana kamar mandi, sarana tempat cuci, dan sarana kakus. Ini bisa dijadikan sebagai acuan penilaian standar sebuahMCK. Contohya : sarana kamar mandi dilengkapi dengan atap, bak air dan pintu. Jalan masuk ke kamar mandi yang dilengkapi dengan pintu harus dibuat sedemikian rupa sehingga orang yang sedang mandi tidak terlihat langsung dari luar (Raihani et al., 2020).

Pada gambar 1 di bawah ini, tampak MCK darurat milik warga yang terbuat dari daun gewang dengan air pembuangan yang tergenang serta kondisi kamp yang becek dan berlumpur ketika musim hujan.

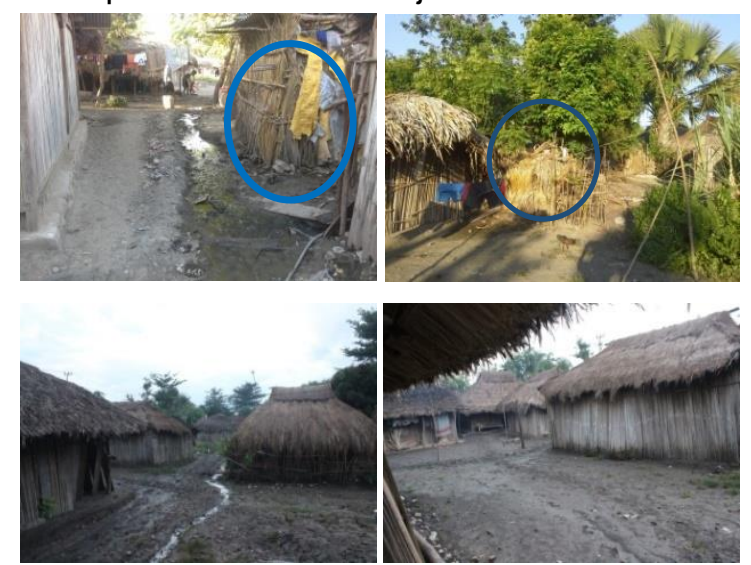

Gambar 1. MCK Darurat (lingkaran biru) Milik

Warga (atas) dan Kondisi Lingkungan Saat Hujan (bawah)
Mayoritas warga/KK bermata pencaharian sebagai buruh tani yang 
menggarap lahan sawah/kebun milik penduduk asli kemudian hasilnya dibagi. Aktifitas ini pun hanya dilakukan pada saat musim hujan (Desember - Maret), selanjutnya mereka bekerja serabutan sebagai buruh kasar (bangunan), buruh tambak garam bahkan ada yang tidak bekerja. Beberapa KK memelihara kambing dan babi, namun mereka pun kesulitan dalam hal pakan ternak sehingga pertumbuhan ternak babi pun terkesan lamban. Kandang yang dibangun pun tidak jauh dari rumah tempat tinggal, sehingga menimbulkan bau yang kurang sedap.

Kegiatan yang dilakukan ini bertujuan untuk menyediakan MCK, khususnya untuk ketersedian tempat buang air besar (BAB) warga yang layak dan memenuhi standar minimal kesehatan.

\section{METODE}

Kegiatan ini dilaksanakan di kamp pengungsi Dilor, Desa Tuapukan, Kecamatan Kupang Timur, Kabupaten Kupang, NTT. Wilayah ini berjarak $\pm 20 \mathrm{~km}$ dari Kota Kupang. Mitra dari kegiatan ini adalah Pemuda Galak yang berada di wilayah kamp pengungsi yang berjumlah 17 orang. Kegiatan ini diawali dengan survei dan wawancara dengan warga untuk mendapatkan informasi terkait dengan kebutuhan mendasar yang mesti dipenuhi. Pada tahapan ini tercatat beberapa problem, dan akhirnya disepakati untuk membangun MCK. Pada kesempatan ini, tim pelaksana menyampaikan bahwa MCK yang dibangun hanya 1 unit, namun warga meminta kepada tim pelaksana untuk membangun 2 unit MCK, 1 unit di bagian barat dan 1 unit lagi di bagian timur. Hal ini untuk mengurangi kecemburuan sosial sesama warga. Setelah berembuk, tim pelaksana menyetujui usulan warga dengan catatan bahwa bangunan MCK tidak perlu diplester bagian luarnya serta setiap unit MCK memiliki 3 buah kamar mandi dan closet.

Bahan-bahan yang dibutuhkan adalah:

1. Batu karang 5 Ret (pondasi bangunan dan pasangan dinding septic tank)

2. Batako, 800 buah

3. Semen 65 sak

4. Pasir kali 2 ret

5. Closetjongkok 6 buah

6. Kerikil 3 kubik

7. Seng 20 lembar

8. Seng Licin 6 lembar

9. Kusen pintu 6 buah

10. Kayu usuk $5 \times 7$, sebanyak 40 batang

11. Besi beton $10 \mathrm{~mm}$, sebanyak 30 batang

12. Besi beton $6 \mathrm{~mm}$, sebanyak 6 batang

13. Tripleks $8 \mathrm{~mm}$, sebanyak 6 lembar.

14. Pipa Paralon 4 dim

15. Kawat lkat, sebanyak $1 \mathrm{~kg}$

\section{Paku Seng}

Semua bahan tersebut disiapkan oleh tim pelaksana, sedangkan dalam pengerjaannya dibantu oleh warga secara gotong royong dan seorang tukang yang disiapkan oleh tim pelaksana.

\section{HASIL DAN PEMBAHASAN \\ Penggalian Lubang Septic tank}

Lubang septic tankdibuat dengan ukuran panjang $3 \mathrm{~m}$, lebar $2 \mathrm{~m}$ dan dalam $2 \mathrm{~m}$. proses penggalian dilakukan secara manual selama 1 (satu) minggu oleh warga secara gotong royong. Proses penggalian tidak mengalami kendala karena lokasi galian tanah tanpa batuan. Selanjutnya dilakukan pemasangan batu karang pada dinding bagian dalam septic tank selama 1 minggu. Tanah bekas galian digeser sejauh 1 (satu) meter dari pinggir lubang, dan sebagian dipakai untuk menimbun pondasi rumah MCK. Pada Gambar 2 di bawah ini, tampak warga sementara melakukan aktifitas penggalian 2 buah lubang septic tankdengan menggunakan linggis dan sekop, yang disaksikan oleh tim pelaksana.

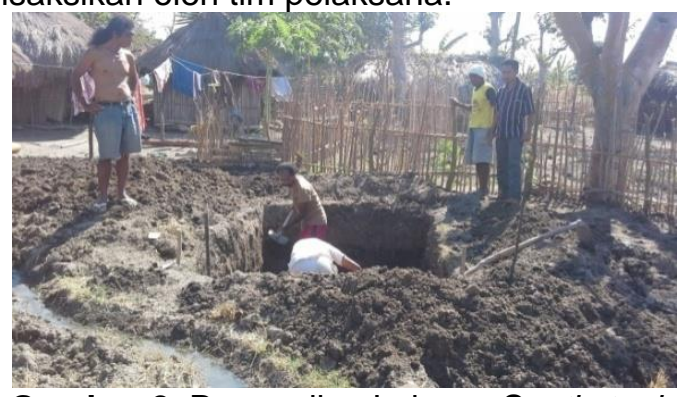

Gambar 2. Penggalian Lubang Septic tank, Bagian Timur (atas)

\section{Pemasangan Batu pada Dinding Bagian Dalam}

Untuk mencegah terjadinya longsor atau runtuh pada dinding septic tank, maka dilakuan pemasangan batu karang pada diding bagian dalam septic tank. Bagian bawa/dasar diberi pondasi batu karang selebar $40 \mathrm{~cm}$, kemudian dilanjutkan dengan pemasangan dinding selebar $30 \mathrm{~cm}$. Sedangkan pada bagian sudut (4 sudut) diberi tiang yang dicor sehingga tidak mudah rubuh atau ambruk saat musim penghujan. Untuk meningkatakan kekuatan maka, komposisi perbandingan campuran semen dan pasir saat pemasangan adalah 4:1 (4 pasir, 1 Semen).Proses pemasangan dinding septic tank di bagian barat dan bagian timur dilakukan selama 1 (satu) minggu.

Hasil pemasangan dinding septic tankdapat dilihat pada Gambar 3. Pada gambar, tampak ketua Pemuda Galak sementara melihat lubang septic tank di bagian timur yang telah terpasang. 


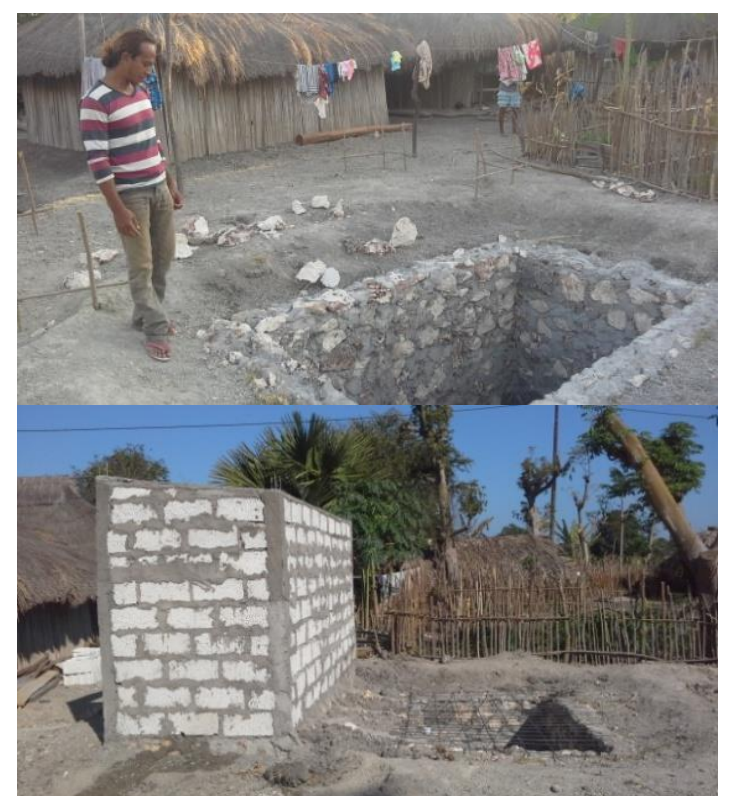

Gambar 3. Hasil Pemasangan Dinding Lubang Septic tank, Bagian Timur (atas) dan Bagian Barat (bawah)

\section{Pengecoran Septic tank}

Setelah selesai pemasangan dinding dinding septic tank, dilanjutkan dengan pengerjaan sloof dibagian atas dinding. Sebelum pengecoran, terlebih dahulu dibuatkan anyaman besi beton (tikar)dengan jarak antara besi adalah $10 \mathrm{~cm} \times 10 \mathrm{~cm}$ serta penahan/bagesting dari papan tripleks dan kayu (di bagian dalam). Adapun proses pengecoran dapat dilihat pada Gambar 4 .

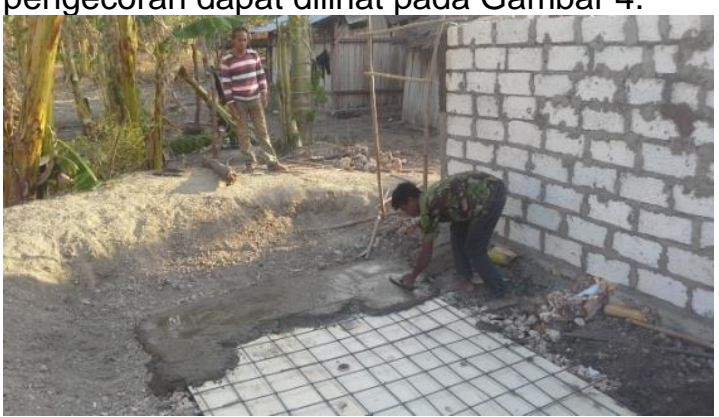

Gambar 4. Pengecoran Septic tank

Perbandingan campuran pada pengecoran septic tank adalah 3:2:1 (3 Pasir, 2 Kerikil dan 1 Semen) dengan ketebalan pengecoran $12 \mathrm{~cm}$. Pada bagian atas pengecoran, diletakan pipa buang udara berdiameter 2 inch. Hasil coran septic tank dapat dilihat pada Gambar 5 di bawah ini.

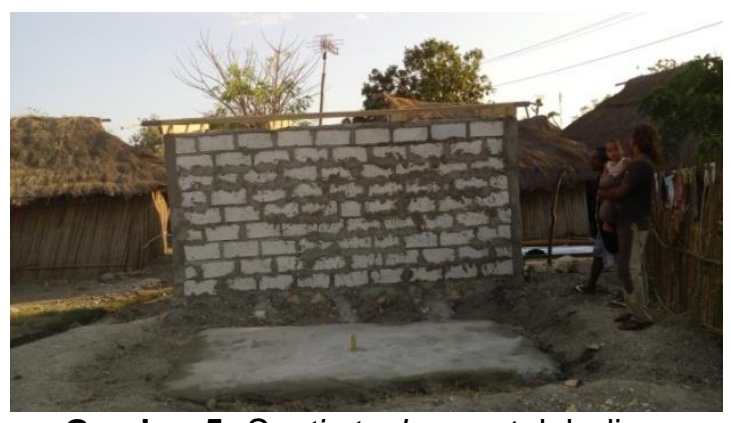

Gambar 5. Septic tank yang telah dicor

\section{Pengerjaan Bangunan MCK}

Bangunan MCK menggunakan bahan batakodengan jumlah kamar sebanyak 3 buah setiap MCK sehingga total ada 6 kamar yang dibangun dengan ukuran MCK adalah tinggi 2.2 meter, lebar 1,6 meter dan panjang 4,8 meter. Setiap kamar dilengkapi dengan 1 closet sehigga total ada 6 buah closet jongkok yang bisa digunakan untuk BAB oleh warga. Pada Gambar 6, terlihat kedua bangunan MCK yang telah dikerjakan.

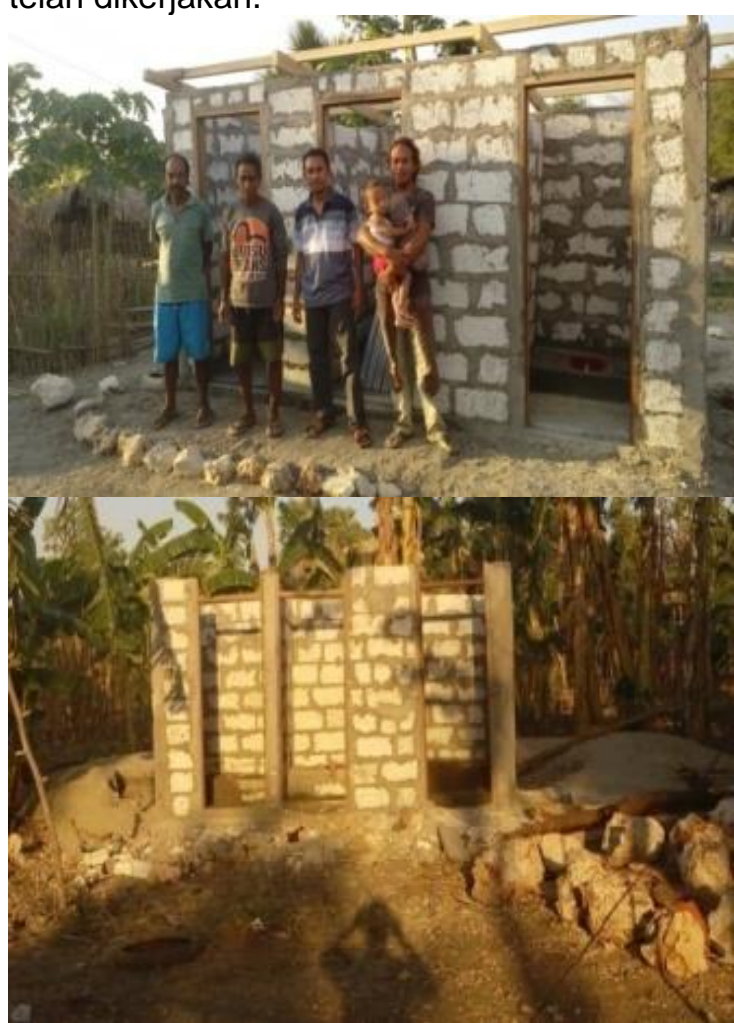

Gambar 6. Bangunan MCK bagian Timur (kiri) dan bagian barat (kanan) yang dilengkapi dengan closet

\section{Atap dan Pintu}

Atap bangunan MCK menggunakan material atapseng, sedangkan daun pintu menggunakan seng licin. Penggunaan seng licin pada pintu untuk meminimalisir kerusakan daun pintu seperti terlihat pada Gambar 7. 


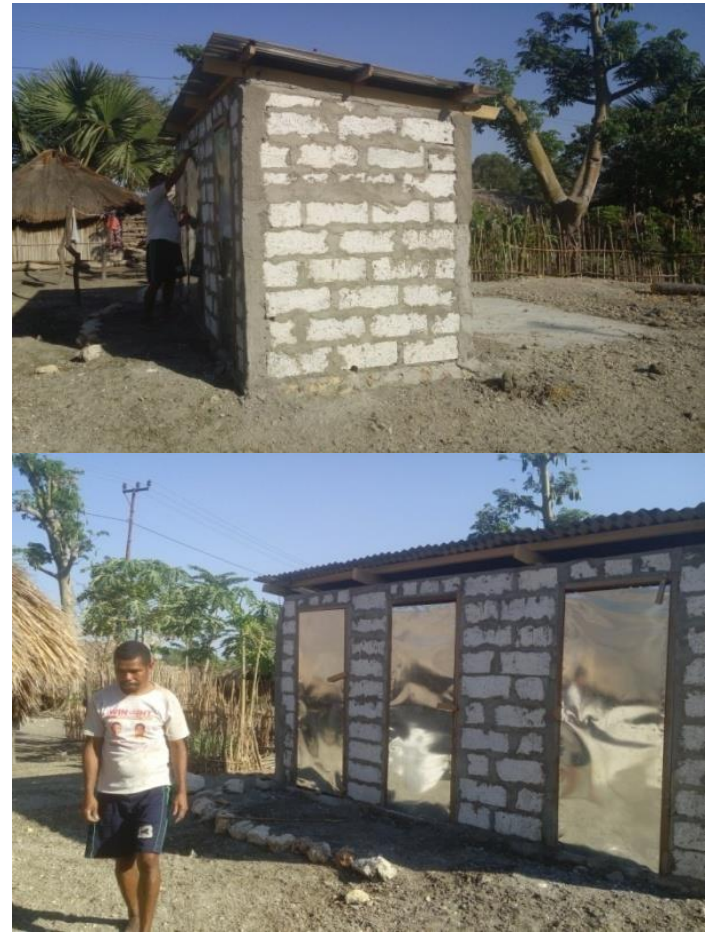

Gambar 7. Bangunan MCK yang telah diatap dan dipasang pintu

\section{Penyuluhan}

Selain kegiatan pembangunan fisik MCK, tim pelaksana juga memberikan penyuluhan tentang pola hidup bersih dan sehat (PHBS) dengan melibatkan dosen dari fakultas Kesehatan Masyarakat. Tujuan penyuluhan ini agar warga tidak lagi $B A B$ sembarangan dan dapat memanfaatkan MCK yang ada untuk Mandi dan BAB. Selain itu, warga juga diberi penyuluhan tentang pemanfaatan pekarangan untuk tanaman sayuran organic di polibag sebagai upaya memenuhi kebutuhan sayuran bagi keluarga.

Salah seorang warga, yang juga merupakan ketua pemuda di kamp pengungsi mencoba mengaplikasikan tanaman sayuran pada media polibag. Hasilnya dapat dilihat pada Gambar 8.

Untuk mengetahui penggunaan MCK oleh warga, maka tim pelaksana melakukan monitoring sebanyak $2 x$ sebulan selama 3 bulan. Hasil pantauan tim pelaksana di lokasi kegiatan setelah kegiatan ini dilaksanakan, terlihat warga sudah menggunakan MCK dan tidak lagi BAB sembarangan. Tim pelaksana juga selalu memantau atau meminta informasi dari ketua pemuda melalui telpon terkait penggunaan MCK.

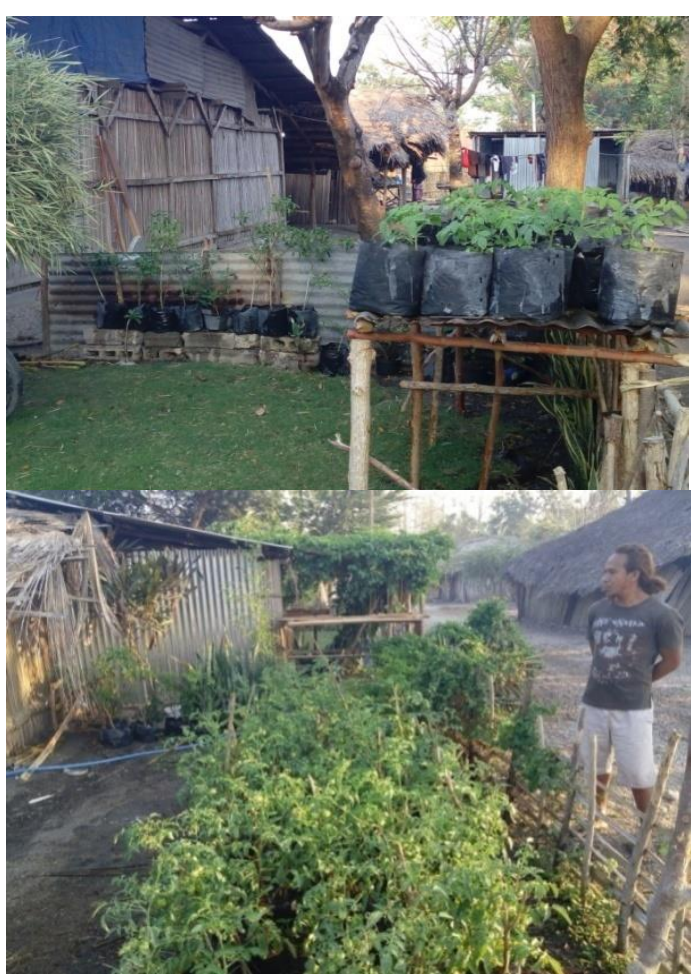

Gambar 8. Pekarangan Rumah Ketua Pemuda di Kamp Pengungsi Yang telah ditanami tomat, Lombok dan sayuran

\section{SIMPULAN DAN SARAN Simpulan}

Kegiatan ini menghasilkan dua unit MCK siap pakai dan warga tidak lagi $B A B$ sembarangan. Air pada saluran pembuangan MCK darurat selalu dibersihkan sehingga tidak terdapat genangan air.

\section{Saran}

Warga kamp pengungsi perlu
diedukasi dan diberdayakan untuk memanfaatkan lahan kosong di sekitar kamp dengan cara menanam tanaman holtikultura.

\section{UCAPAN TERIMAKASIH}

Terimakasih kepada Pimpinan LPM Universitas Nusa Cendana yang telah mendanai kegiatan pengabdian ini.

\section{DAFTAR RUJUKAN}

Moh Soehadha. (2019). KOMUNITAS EKS PENGUNGSI TIMOR TIMUR Pendahuluan. 13(April), 351-378.

Mulia, Y. (2014). Upaya Indonesia Dalam Repatriasi Warga Eks Timor Timur (2000 - 2012). Jurnal Online Mahasiswa (JOM) Bidang IImu Sosial Universitas Riau, No. 1(2), 77-82. jom.unri.ac.id

Nasional, B. S. (2002). Tata cara perencanaan bangunan mck umum (Vol. 2002).

Raihani, F., Chadirin, Y., Putra, H., Aleksandria, T., Amelia, R., Ganda, G. R., Chairunnisa, 
N., Andriani, F., Lubis, S., Kandyas, M. A., Teknik, D., Pertanian, F. T., \& Pertanian, I. (2020). Desain Instalasi Mandi , Cuci , dan Kakus di Cipapais , Kelurahan Kadumerak , Kabupaten Pandeglang ( Design of Bathing, Washing and Toilet Installation in Cipapais, Kadumerak Village, Pandeglang Prefecture ). Jurnal Pusat Inovasi Masyarakat ISSN 2721897X, 2(3), 513-518.

Sutoyo, E., Pramono, S. D., \& Pawesti, K. W. (2019). Pemanfaatan Mck Sebagai Salah Satu Upaya Peningkatan Perilaku Hidup Bersih Dan Sehat (Phbs) Warga Rt 04/01 Desa Sadeng. Abdi Dosen: Jurnal Pengabdian Pada Masyarakat, 3(3), 208215. 